\title{
Effects of Coolant Flow Characteristics and Channel Surface Temperature on Nucleate Boiling Heat Transfer in IC Engine Cooling System
}

\author{
Haoyu Chen ${ }^{1)}$ Emir Yilmaz ${ }^{1)}$ Koki Asano ${ }^{1)}$ Ryota Shindo ${ }^{1)}$ Ayumi Homma ${ }^{1)}$ \\ Naoya Kimata ${ }^{1)}$ Takashi Suzuki $^{2)}$ Mitsuhisa Ichiyanagi ${ }^{2)}$ \\ 1) Sophia University, Graduate School of Science and Technology \\ 7-1 Kioi-cho, Chiyoda-ku, Tokyo, 102-8554, Japan \\ 2) Sophia University, Department of Engineering and Applied Sciences \\ 7-1 Kioi-cho, Chiyoda-ku, Tokyo, 102-8554, Japan
}

Received on June 30 ,2020

\begin{abstract}
To improve the thermal efficiency of ICEs, effective control of in-cylinder temperature is important. Utilization of nucleate boiling phenomenon to model the heat transfer is one of the measures that can be used for this purpose. Surface heat flux and bubble departure frequency measurements were done under the different wall superheat, coolant flow-rate, and temperature conditions. Subsequently, dimensional analyses were done to investigate the necessary dimensionless numbers acting on the heat flux model. The addition of power and exponential function of Jakob number was found to be effective, resulting in an average and minimum errors of $11.2 \%$ and $6.5 \%$, respectively.
\end{abstract}

KEY WORDS: heat fluid, refrigerant, engine cooling, thermal management, forced flow nucleate boiling, heat transfer [D1]

\section{Introduction}

For the past decade, in order to improve the thermal efficiency of internal combustion engines (ICEs) and reduce the size of heat exchangers for EGR coolers, effective thermal management of automobiles is required. Thermal management and control technologies using a nucleate boiling heat transfer model are being expected, which are able to control the coolant temperature at a higher level to reduce heat loss and have both high cooling efficiency and reliability.

Regarding previous models, Rohsenow ${ }^{(1)}$ suggested a theory that forced flow nucleate boiling heat flux is superimposed of forced convection heat flux and nucleate boiling heat flux. Chen ${ }^{(2)}$ using Forster-Zuber model ${ }^{(3)}$ and Rohsenow's superposition theory ${ }^{(1)}$, proposed correction factors for the superimposed heat flux in saturated nucleate boiling. Steiner et al. ${ }^{(4)}$ improved Chen's correction factors by observing the behavior of bubbles under forced flow and using bubble dynamics. Although these models have been proved that can accurately predict nucleate boiling heat flux in simple coolant operation conditions, the influence of the surface properties (surface roughness and materials) and the channel shape change cannot be expressed by these models. Hence, there are few models that can be applied in a cooling system in ICE which has different surface properties and complex coolant-channel shapes, such as the narrow flow paths around the exhaust valve and between the two cylinders.

In this study, due to the above reasons, the effective control factors (flow rate, temperature, system pressure, flow path specification, etc.) of the nucleate boiling phenomenon will be verified in an experimental apparatus, and an empirical model will be proposed, which can accurately predict the occurrence of nucleate boiling phenomenon and the heat flux in the coolant system of an ICE. In this paper, an experimental apparatus that has a channel with a horizontal heating surface to simulate the flow conditions of coolant in ICE is constructed. Subsequently, using water as the coolant liquid, the surface heat flux changes were analyzed and discussed under the conditions of the flow velocities $0.58 \mathrm{~m} / \mathrm{s}-0.96 \mathrm{~m} / \mathrm{s}$ and the coolant temperature as $80{ }^{\circ} \mathrm{C}$ and $95{ }^{\circ} \mathrm{C}$. Additionally, the physical phenomena that involved the heat flux prediction were integrated into dimensionless numbers through dimensional analysis. And through correlation analyses, it was found that there is a good correlation between the product of the power function and exponential function of the dimensionless number Jakob number, $J a$, which expresses the relationship between superheat and bubble generation. This lays the foundation for the proposed model.

\section{Literature Overview}

The previous studies, many forced flow nucleate boiling models followed the Rohsenow's superposition theory ${ }^{(1)}$ that the total heat flux of the heating surface, $q_{w}$, can be assumed to be the addition of two contributions, which can be written as:

$q_{w}=q_{l c}+q_{p o o l}$

The first term, $q_{l c}$, is the heat flux due to forced convection, and the second term, $q_{p o o l}$, is due to nucleate boiling.

For the subcooled nucleate boiling heat flux prediction, Steiner et al. followed the superposition theory into the modeling approach and observed the bubble growth behavior in the subcooled flow. According to the bubble dynamics and the influence of the thickness of the superheated layer and the temperature boundary layer to the bubble formation, the correction coefficients were suggested as $S_{\text {flow }}$ and $S_{s u b}$, and the following model was proposed as: 
Vol.11, No.4(2020)

$q_{w}=q_{l c}+S_{f l o w} S_{s u b} q_{\text {pool }}$

$S_{\text {flow }}=r_{D} / r_{L}$

$S_{s u b}=\frac{T_{w}-T_{s}}{T_{w}-T_{l}}$

where $r_{D}$ : bubble departure radius [m], $r_{L}:$ bubble lift-off radius [m], $T_{w}$ : wall temperature $\left[{ }^{\circ} \mathrm{C}\right], T_{s}$ : liquid saturate temperature $\left[{ }^{\circ} \mathrm{C}\right], T_{l}$ : liquid temperature $\left[{ }^{\circ} \mathrm{C}\right]$. The first term due to the forced convection and the second term due to the nucleate boiling is calculated using Dittus-Boelter model ${ }^{(5)}$ and Forster-Zuber model $^{(3)}$, respectively, as:

$$
\begin{aligned}
& q_{\text {lc }}=0.023 \operatorname{Re}_{l}^{0.8} \operatorname{Pr}_{l}^{0.4}\left(k_{l} / d\right)\left(T_{w}-T_{l}\right) \\
& q_{\text {pool }}=0.00122\left(\frac{\lambda_{l}^{0.79} c_{p l}^{0.45} \rho_{l}^{0.49}}{\sigma^{0.5} \mu_{l}^{0.29} h_{l g}^{0.24} \rho_{v}^{0.24}}\right)\left(\Delta T_{\text {sat }}\right)^{1.25}\left(\Delta P_{\text {sat }}\right)^{0.75}
\end{aligned}
$$

where $\operatorname{Rel}_{l}$ : liquid Reynolds Number [-], $\mathrm{Prl}$ : liquid Prandtl number $[-], \lambda_{l}:$ liquid conductivity $[\mathrm{W} / \mathrm{m}-\mathrm{K}], d:$ pipe diameter $[\mathrm{m}], c_{p l}$ : specific heat capacity $\left[\mathrm{J} / \mathrm{kg}^{\circ}{ }^{\circ} \mathrm{C}\right], \rho_{l}$ : liquid density $\left[\mathrm{kg} / \mathrm{m}^{3}\right], \sigma:$ surface tension $\left[\mathrm{N} / \mathrm{m}^{2}\right], \mu_{l}$ : liquid viscosity [Pa-s], $h_{l g}$ : latent heat of vaporization $[\mathrm{J} / \mathrm{kg}], \rho_{v}$ : vapor density $\left[\mathrm{kg} / \mathrm{m}^{3}\right]$, $\Delta T_{\text {sat }}$ : superheat $\left[{ }^{\circ} \mathrm{C}\right], \Delta P_{\text {sat }}$ : difference in vapor pressure corresponding to $\Delta T_{\text {sat }}[\mathrm{Pa}]$.

\section{Experimental Setup and Method}

\subsection{Experimental apparatus}

\subsubsection{Experimental coolant channel apparatus}

The experimental device is designed to simulate the running coolant fluid in an actual operation of ICEs' coolant system. Table 1 shows surface properties, channel diameter and the operating conditions of the coolant channel in an actual ICE, and the experimental coolant channel schematic diagram is shown in Figure 1. This closed-loop channel is constructed with three different parts: the main channel for surface heat flux measurement and bubble observation, a filtration channel, and a return channel. The mainline contains a variable output electric water pump, a plug heater, an accumulator, a flowmeter, a rectangle observation channel with a horizontal heating surface, a flow-rate adjustment valve and a relief valve. The experimental instruments are shown in Table 2. The flow in the channel is generated by an electric pump, and the flow-rate was adjusted by the inverter of the pump and the flow-rate adjustment valve. During the preparation phase before the experiment, the working liquid can be filtered through the filtration channel. After the filtration, the coolant flow passes through the plug heater, so that the working fluid is heated. Then the pressure pulse in the channel is absorbed by the horizontally set accumulator and the system pressure of the channel can be adjusted through controlling the nitrogen pressure in the accumulator. After measuring the flowrate through a flowmeter, coolant liquid is heated by the horizontal heating surface. Surface heat flux is measured by thermocouples, which are inserted in the heating section and bubbles are observed by high-speed camera through the glass windows. In order to clarify the effect of the heating surface properties on the heat flux, the heating surface was changed to several different surface roughness and materials.

\begin{tabular}{|c|c|c|}
\hline & & Range \\
\hline \multicolumn{2}{|c|}{ Maximum flow velocity (Average) $[\mathrm{m} / \mathrm{s}]$} & 5 \\
\hline \multicolumn{2}{|c|}{ Coolant temperature $[\mathrm{K}]$} & $313-383$ \\
\hline \multicolumn{2}{|c|}{ Coolant pressure $[\mathrm{MPa}]$} & $0.10-0.27$ \\
\hline \multicolumn{2}{|c|}{ Average heat flux $\left[\mathrm{MW} / \mathrm{m}^{2}\right]$} & 2 \\
\hline \multirow{2}{*}{ Surface roughness } & $R a[\mu \mathrm{m}]$ & $0.2-15$ \\
\hline & $R z[\mu \mathrm{m}]$ & $3.0-72$ \\
\hline \multicolumn{2}{|c|}{ Channel diameter (Average) [mm] } & $7.9-12$ \\
\hline
\end{tabular}

Table 1 Operating conditions in cooling channel of ICE.

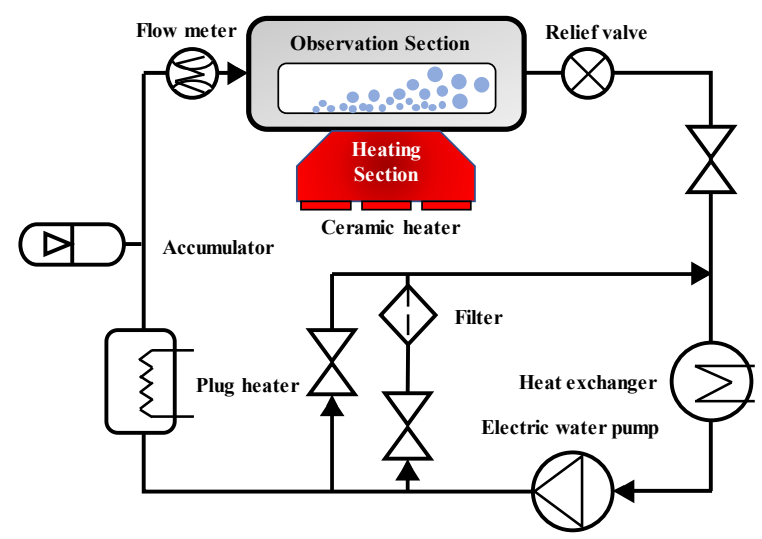

Figure 1 Schematic of experimental channel structure of heated closed-loop cooling system with an observation channel.

\begin{tabular}{|c|c|c|}
\hline Instrument & Manufacturer & Type \\
\hline Electric water pump & Ebara Corp. & 40LPS52.2E \\
\hline Plug heater & $\begin{array}{l}\text { Hakko Electric } \\
\text { Co., Ltd. }\end{array}$ & SWP3060 \\
\hline Accumulator & $\begin{array}{c}\text { Eagle Industry } \\
\text { Co., Ltd }\end{array}$ & ME70-300-30 \\
\hline Ceramic heater & $\begin{array}{l}\text { Sakaguchi E.H } \\
\text { Voc Corp. }\end{array}$ & MS-1000 \\
\hline $\begin{array}{l}\text { High speed camera } \\
\text { (Horizontal direction) }\end{array}$ & $\begin{array}{l}\text { nac Image Tech. } \\
\text { Inc. }\end{array}$ & $\begin{array}{l}\text { MEMRECAM } \\
\text { ACS-1 } \\
\end{array}$ \\
\hline $\begin{array}{l}\text { High speed camera } \\
\text { (Vertical direction) }\end{array}$ & Photron Ltd. & $\begin{array}{c}\text { FASTCAM Mini } \\
\text { UX50type }\end{array}$ \\
\hline
\end{tabular}

Table 2 Experimental instruments.

\subsubsection{Observation and measurement section}

The schematic of the observation sections and the heating section are shown in Figure 2. To implement the horizontal plane heating, a $30 \times 30 \mathrm{~mm}$ rectangle channel is designed to be assembled from top, side (left and right) and bottom block. Two glass observation windows and one polycarbonate LED light source window, $20 \times 60 \mathrm{~mm}$, are set on the front, back and top sides of the channel. Bubble growth process, the departure frequency and the boiling area fractions are captured by two highspeed cameras, which were set in the horizontal and vertical directions of the heating surface. Additionally, according to the requirements of the experiment, the channel height was designed to be changed by replacing the top block with different thicknesses, and the achievable heights of 5, 10, 15, 20, $30 \mathrm{~mm}$. Regarding the heating section, a heating block designed to achieve the heat concentration on the heating surface is inserted into the bottom block of the channel, according to the FEM 
thermal analyses result. On the bottom of the heating block, six $555 \mathrm{~W}$ output aluminum substrate ceramic heaters are set to ensure the heat flux of the heating surface. On the top of the heating block, a total of nine K-type thermocouples with a diameter of $0.5 \mathrm{~mm}$ were installed and the heat flux at the upper, middle, and lower parts of the heating surface is measured. To ensure the measurement accuracy, all thermocouples were calibrated by ice-water mixture and boiling water, which is $0{ }^{\circ} \mathrm{C}$ and $100{ }^{\circ} \mathrm{C}$, respectively. Regarding to the heating surface, to analyze the influence of the surface properties, in terms of micro shape on the surface, the top surface of the heating block is processed by EDM to specified surface roughnesses, $R a=3,15$, $30 \mu \mathrm{m}$. In terms of different surface materials, aluminum, cast iron, and stainless steel will be used.

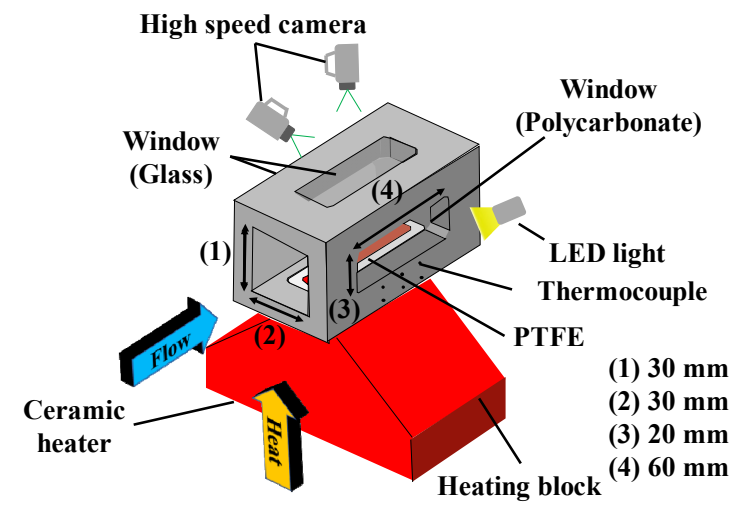

Figure 2 Schematic of rectangle channel with heating section.

Table 3 Experimental conditions.

\begin{tabular}{|c|c|}
\hline Channel width $[\mathrm{mm}]$ & 30 \\
\hline Channel height $[\mathrm{mm}]$ & 30 \\
\hline Coolant component & water \\
\hline Surface roughness, $R a[\mu \mathrm{m}]$ & 3 \\
\hline Heating surface material & Aluminum \\
\hline Pressure $[\mathrm{MPa}]$ & 0.11 \\
\hline $\begin{array}{c}\text { Observation section flow velocity } \\
{[\mathrm{m} / \mathrm{s}]}\end{array}$ & $0.58,0.68,0.84,0.96$ \\
\hline Coolant temperature $\left[{ }^{\circ} \mathrm{C}\right]$ & 80,95 \\
\hline Heating surface temperature $\left[{ }^{\circ} \mathrm{C}\right]$ & $94-130$ \\
\hline
\end{tabular}

\subsection{Experimental conditions}

In this study, the experiments were carried out with the conditions shown in Table 3 . In the $30 \times 30 \mathrm{~mm}$ rectangular channel, an aluminum heating surface, with a roughness of $3 \mu \mathrm{m}$, is heated at the flow temperature of $80{ }^{\circ} \mathrm{C}, 95{ }^{\circ} \mathrm{C}$ and the flow velocity range of $0.58 \mathrm{~m} / \mathrm{s}-0.96 \mathrm{~m} / \mathrm{s}$. Through controlling the output of the ceramic heater, the temperature of the heating surface is changed between $94{ }^{\circ} \mathrm{C}-130{ }^{\circ} \mathrm{C}$. At the same time, the surface heat flux measurement and the bubble growth process observations were carried out.

\subsection{Method of heat flux and surface temperature calculations}

In this study, the heat transfer in the heating block is assumed to be linear (1D) and the heat flux calculation equation is written by using Fourier's law of conduction:

$q_{w}=\lambda \frac{\Delta T}{\Delta l}$

where $\lambda:$ thermal conductivity $\left[\mathrm{W} / \mathrm{m}-{ }^{\circ} \mathrm{C}\right], \Delta T:$ temperature difference between ends $\left[{ }^{\circ} \mathrm{C}\right], \Delta l:$ distance between ends $[\mathrm{m}]$. The heating surface temperature was calculated from the calculated heat flux by using the following equation:

$T_{w}=T_{1}-\frac{q_{w}}{\lambda} l$

where $T_{1}$ : top measuring position temperature $\left[{ }^{\circ} \mathrm{C}\right], l$ : distance between heating surface and top measuring position $[\mathrm{m}]$.

\section{Results and Discussion}

\subsection{Surface heat flux measurement and bubble observation}

Figures 3 and 4 show the effect of coolant flow velocity and coolant temperature on surface heat flux. $0.84 \mathrm{~m} / \mathrm{s}$ is selected as the flow velocity presented. According to the observation results of the high-speed camera located in the vertical direction of the heating surface, the data measured without boiling at low overheating is indicated by marks of $\times$. From the results of the experiments, the enhancement effect of nucleate boiling on heat flux can be confirmed. By comparing the heat flux measurement results in Figure 3, the heat flux at each temperature at the flow velocity of $0.58 \mathrm{~m} / \mathrm{s}$ is lower than the measured value at the condition of the flow velocity of $0.96 \mathrm{~m} / \mathrm{s}$. This can be attributed to the forced convection enhancement due to the increase of Reynolds Number in the channel with the increase of the flow velocity. With regard to the effect of the coolant temperature on the heating surface heat flux, the measured average heat flux at the coolant temperature of $80{ }^{\circ} \mathrm{C}$ was increased by $0.18 \mathrm{MW} / \mathrm{m}^{2}$ due to the larger temperature difference at the same surface temperature, compared with the coolant temperature of $95^{\circ} \mathrm{C}$, as shown in Figure 4. In order to observe the behavior of bubbles with forced flow nucleate boiling, a high-speed camera placed in the horizontal direction is used to observe the bubble formation. A bubble growth cycle photograph is taken at a coolant temperature of $80^{\circ} \mathrm{C}$, at a flow velocity of $0.96 \mathrm{~m} / \mathrm{s}$, and superheat of $17^{\circ} \mathrm{C}$ at a recording speed of 40,000 fps (frame interval of $0.075 \mathrm{~ms}$ ) is shown in Figure 5. At this coolant temperature, the rapid disappearance of bubbles after lift-off from the heating surface is confirmed (see frame (4) to frame (6)). This was due to the lower coolant temperature than the saturation temperature of the fluid. After the bubbles have detached and left the superheated layer, the vapor condensation in the bubbles causes the disappearance of the bubbles. In addition, the measured results of the average bubble departure frequency of the five positions at different superheating are shown in Figure 6. The departure frequency was calculated by using the sum of the bubble growth time, $t_{g}$ and the waiting time between the bubble departure and the next bubble generation, $t_{w}$. It can be confirmed that as the superheat rises, the bubble departure frequency tends to increase, and reaches 1,195 $\mathrm{Hz}$ when the superheat is $24{ }^{\circ} \mathrm{C}$. 
Vol.11, No.4(2020)

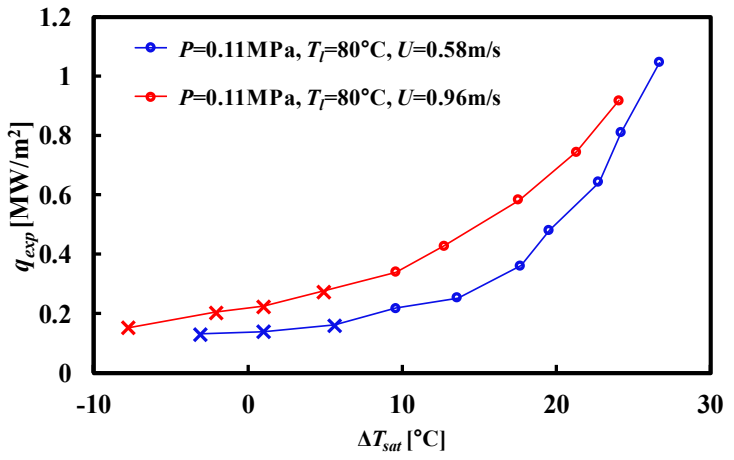

Figure 3 Heat flux measured at coolant temperature of $80^{\circ} \mathrm{C}$ and two different flow velocity of 0.58 and $0.96 \mathrm{~m} / \mathrm{s}$.

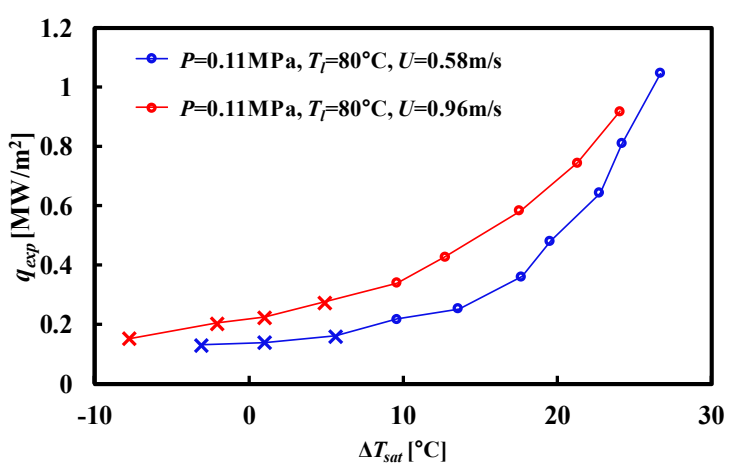

Figure 4 Heat flux measured at flow velocity of $0.84 \mathrm{~m} / \mathrm{s}$ and coolant temperatures of 80 and $95^{\circ} \mathrm{C}$.

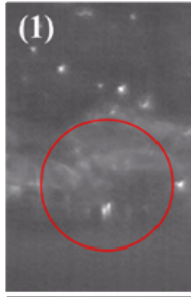

(4)

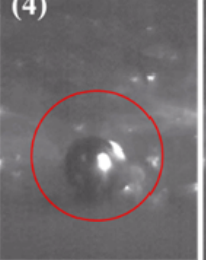

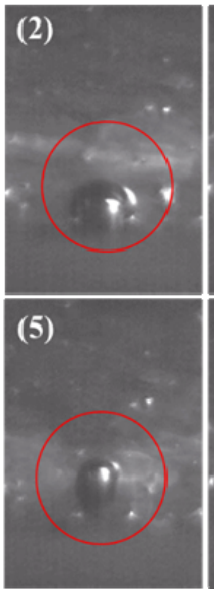

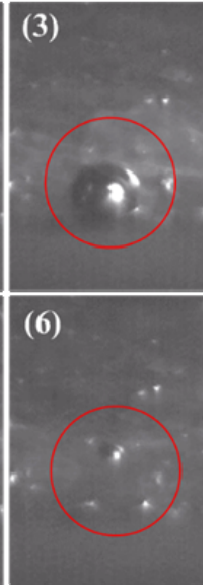

Figure 5 Instantaneous image sequence of one bubble growth cycle at superheat of $17{ }^{\circ} \mathrm{C}$, coolant temperature of $80{ }^{\circ} \mathrm{C}$ and flow velocity of $0.96 \mathrm{~m} / \mathrm{s}$, captured by high-speed camera.

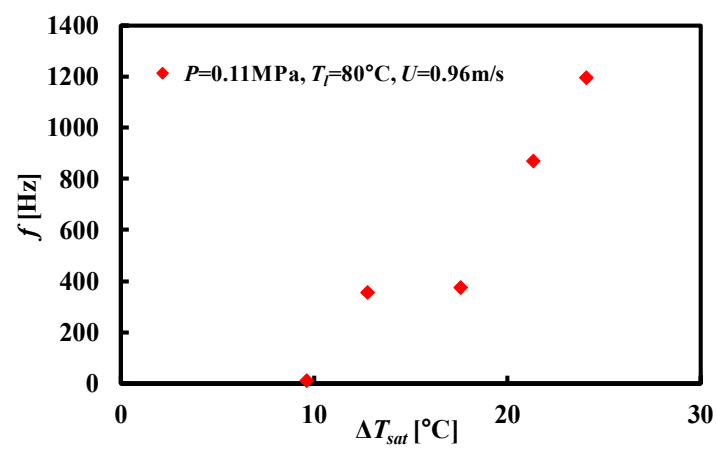

Figure 6 Bubble departure frequency measured at coolant temperature of $80^{\circ} \mathrm{C}$ and flow velocity of $0.96 \mathrm{~m} / \mathrm{s}$.

\subsection{Validation of previous model}

Steiner et al. model which is introduced in Chapter 2 was proposed to be suitable for ICE's cooling system. It considered the influence of flow velocity as well as coolant temperature and it was proved to be in good agreement with their experimental results. Therefore, Steiner et al. model was selected to verify the prediction accuracy using the present experimental results. The present experimental data are compared with the Steiner et al. model, as shown in Figure 7. The results show that the average relative error between the predicted value and the measured value reaches $46.3 \%$, and it is almost impossible to reproduce the rising trend of heat flux due to the nucleate boiling occurrence. After boiling occurs, the changes in heat flux between different flow velocity and coolant temperatures cannot be confirmed. As a result, the second term in equation (1), such as the nucleate boiling effect phenomenon, is decided to be reconstructed.

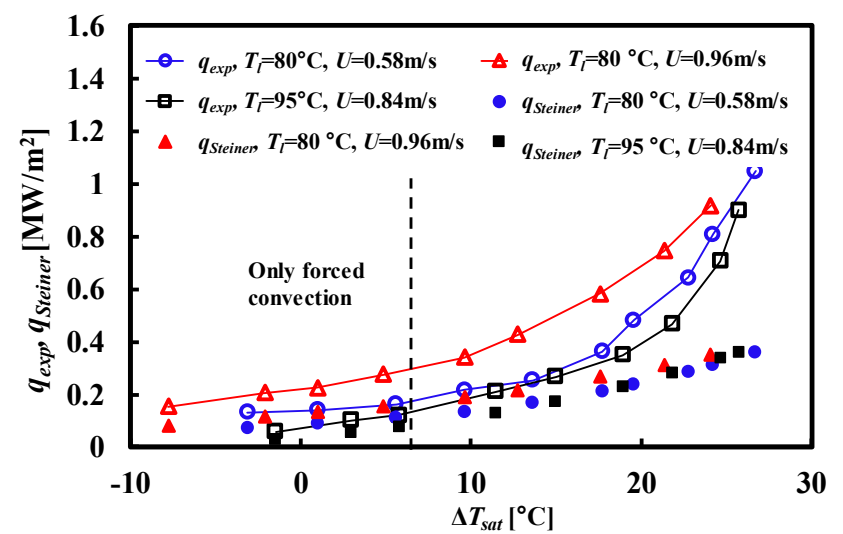

Figure 7 Comparison of predicted surface heat flux from Steiner et al. model and present experimental surface heat flux.

\subsection{Dimensional analyses}

According to the comparison of experimental results and the Steiner et al. model, the calculated results from the predictive model did not show good agreement with the measured nucleate boiling heat fluxes. To construct an accurate model that can predict the surface heat flux dimensional analyses are done, along with the revision of the second term of equation (1). In the process of dimensional analyses, according to the experimental results, the effective factors of nucleate boiling are considered as constant volume-specific heat, superheat, liquid density, viscosity coefficient, flow velocity, departure frequency, characteristic length, surface tension, latent heat of vaporization, thermal conductivity, vapor density, subcooling, and heat flux are considered to create dimensionless numbers. There are 5 basic dimensions of the 13 variables including: $L, M, T, \theta, Q$, which are related to length, mass, time, temperature, and heat, respectively. In order to reflect the effect of superheat, flow velocity, and subcooling on nucleate boiling heat flux, according to the dimensionless Buckingham's $\pi$-theorem, the following dimensionless number groups were created:

$\pi_{1}=\frac{\mu_{l} f}{\rho_{l} U^{2}} \quad \pi_{2}=\frac{\rho_{l} U D}{\mu_{l}} \quad \pi_{3}=\frac{U \mu_{l}}{\sigma}=C a \quad \pi_{4}=\frac{c_{p} \Delta T_{\text {sat }}}{h_{l g}}$ 
$\pi_{5}=\frac{\mu_{l} c_{p}}{\lambda_{l}}=\operatorname{Pr} \quad \pi_{6}=\frac{\rho_{l}}{\rho_{v}} \quad \pi_{7}=\frac{\Delta T_{\text {sub }}}{\Delta T_{\text {sat }}}$

It can be seen that 7 dimensionless numbers containing Prandtl number, $\mathrm{Pr}$, and Capillary number, $\mathrm{Ca}$, related to heat flux are obtained by dimensional analyses. $\mathrm{Ca}$ expresses the relative effect of viscous drag forces versus surface tension forces acting across an interface between liquid and gas, and $\operatorname{Pr}$ is defined as the ratio of momentum diffusivity to thermal diffusivity. Then the dimensionless numbers $\pi_{1}, \pi_{2}, \pi_{4}$, and $\pi_{6}$ can be merged, and the following dimensionless numbers are obtained:

$$
\begin{aligned}
& \pi_{1} \cdot \pi_{2}=\frac{f D}{U}=S r \\
& \pi_{4} \cdot \pi_{6}=\frac{\rho_{l} c_{p} \Delta T_{\text {sat }}}{\rho_{v} h_{l g}}=J a
\end{aligned}
$$

where $S r$, Strouhal number, is a dimensionless number that can describe oscillating flow mechanisms due to bubble lift-off. $J a$, Jakob number, represents the ratio of sensible heat to latent heat.

\subsection{Validation of dimensionless number}

\subsubsection{Validation of the forced convection model}

According to the experimental results, a positive correlation between heat flux and superheat can be easily found. Jakob number, not only expresses the heat transfer in the superheated layer but also used extensively to express the relationship between superheat and bubble radius in the saturated pool boiling bubble growth $\operatorname{model}^{(6)}$. Therefore, in this study, a correlation will be verified between $J a$ and measured heat flux data by curve fitting and correlation analysis on the $J a$ obtained from the dimensional analysis in the previous section. In the correlation analysis, the deterministic coefficient will be used to evaluate the degree of interpretation of independent variables to dependent variables.

Firstly, the forced convection nucleate boiling heat flux in this paper is assumed to the superposition of forced convection heat flux and nucleate boiling heat flux similar to previous studies $^{(2),}$ (4). Therefore, in order to analyze the correlation between the nucleate boiling heat flux qboiling and dimensionless number, it is necessary to remove $q_{l c}$ from experimentally measured heat fluxes. In previous models ${ }^{(2),}{ }^{(4)}$, Dittus-Boelter model (equation (5)) is used to characterize the forced convection term. In order to verify whether the characterization of $q_{l c}$, calculation results obtained by Dittus-Boelter model were compared with the experimental data in Figure 8. From the results of Figure 8, before the occurrence of boiling, the experimentally measured forced convective heat flux shows an overall upward shift of $44.0 \%$ compared to the predicted value of the model. Therefore, to reduce the influence of the prediction error of forced convection heat flux on the accuracy of correlation analysis between $q_{b o i l i n g}$ and $J a$ when removing $q_{l c}$ from experimentally measured heat fluxes, the coefficient of the Dittus-Boelter model was modified while maintaining the exponent of the Re and the $P r$. As a result, the coefficient 0.023 of Dittus-Boelter's model was slightly modified to be 0.038 which was found to have the best fitting with the experimental data. A comparison of experimental data (before boiling) with the calculated results of the modified model is shown in Figure 9. It can be seen that the heat fluxes under various flow velocity conditions are predicted by the modified model within an average relative error of $10.2 \%$.

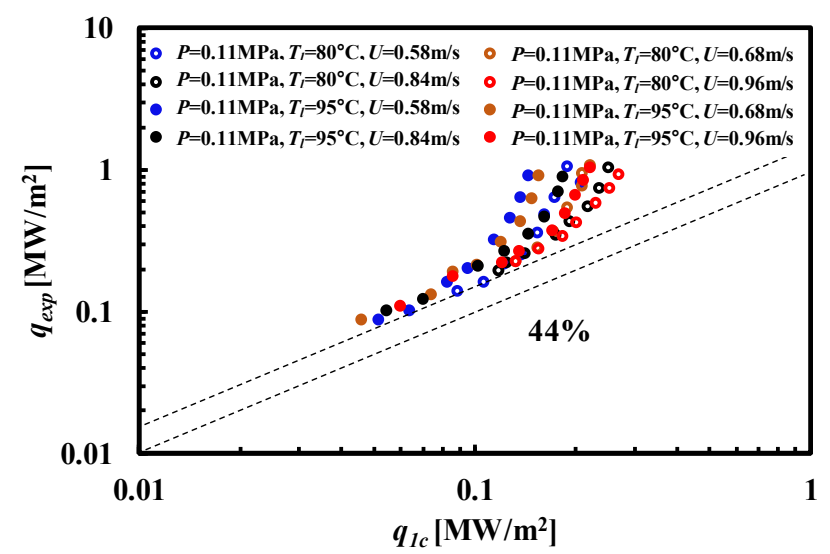

Figure 8 Comparison of predicted surface heat flux from DittusBoelter model and present experimental surface heat flux.

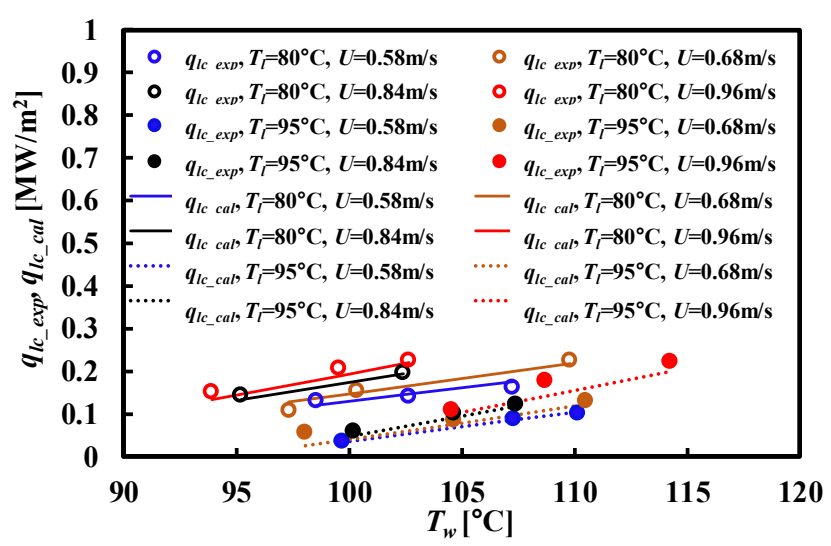

Figure 9 Comparison of predicted surface heat flux from modified Dittus-Boelter model and present experimental surface heat flux during forced convective flow.

4.4.2. Correlation analysis of Jakob number: Power Function Model (PFM)

Before the correlation analysis, data obtained by the heating surface without boiling phenomenon was removed from the following correlation analysis by the observation of the whole area of the heating surface using a high-speed camera located in the vertical direction of the heating surface. Furthermore, $q_{l c}$ in forced flow nucleate boiling is assumed to be unaffected by boiling, similar to Steiner et al. ${ }^{(4)}$. Heat flux due to nucleate boiling is written as:

$q_{\text {boiling_exp }}=q_{\text {exp }}-q_{l c}{ }^{*}$

$q_{l c}{ }^{*}=0.038 \operatorname{Re}_{l}^{0.8} \operatorname{Pr}_{l}^{0.4}\left(k_{l} / d\right)\left(T_{w}-T_{l}\right)$

where the $q l_{c}{ }^{*}$ is the heat flux of forced convection calculated by the modified Dittus-Boelter model. The measured nucleate boiling heat fluxes qboiling_exp calculated by equation (12) with the measured $J a$ as the independent variable are shown in Figure 10. 
Vol.11, No.4(2020)

According to Figure 10, compared with the trend of the fitting curve, it can be seen that almost all the plots of these conditions have a bending trend in which the slopes increase with $J a$ rather than a straight line. The reason can be considered that at the beginning of nucleate boiling, which is greatly affected by forced convection, however, with the increase of superheat, this influence will be weakened due to the increase of the bubble core density and the boiling occurrence area. To verify the correlation between $J a$ and heat flux, PFM is used to fit the curve. The result of the fitting curve is shown in Figure 10. By calculation, the coefficient of the PFM fitting curve is 0.81 . This value means that these two variables have a good correlation and the power function curve is well fitted. Furthermore, according to Zuber's study of the bubble departure diameter in saturated pool boiling ${ }^{(6)}$, the dimensionless bubble growth time can be written as

$$
\frac{D_{d}^{2}}{\alpha_{l} t_{g}}=\pi J a^{2}
$$

where $D_{d}$ : bubble departure diameter $[\mathrm{m}], \alpha_{l}$ : liquid thermal diffusivity $\left[\mathrm{m}^{2} / \mathrm{s}\right]$. In the previous study, the bubble departure frequency $f\left(=1 /\left(t_{w}+t_{g}\right)\right)$, which is the reciprocal of the bubble growth period, is found to be an important factor affecting the nucleate boiling heat flux. Thus, the PFM is used to construct the correlation equation between nucleate boiling heat flux and $J a$. Based on the above analysis, the following assumptions can be made:

$$
q_{\text {boiling }} \propto J a^{n}
$$

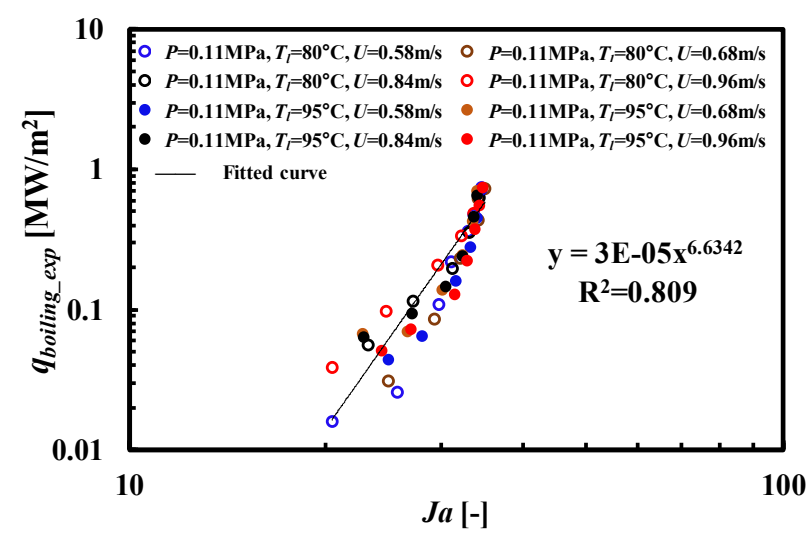

Figure 10 Correlation of nucleate boiling heat flux, qboiling_exp calculated by using equation (12), and Jakob number, $J a$.

Since the heat flux measurement in the present experiment was performed in a $30 \mathrm{~mm} \times 30 \mathrm{~mm}$ channel, and by observation, and bubble stagnancy phenomenon was not observed, the calculated forced flow heat flux by using PFM can be written as:

$$
q_{c a l_{-} 1}=q_{l c}{ }^{*}+q_{\text {boiling_cal } 11}=q_{l c}{ }^{*}+\alpha J a^{n}
$$

where $q_{\text {boiling_cal_1 }}$ is calculated nucleate boiling heat flux by using PFM, and $\alpha$, as well as $n$, are undetermined constant and index number, respectively. To find the optimal solution of the coefficients and exponents of qboiling_cal_1, the least mean square method (LMS) by using experimental heat flux $q_{\exp }$ is used. $\alpha$ is found to be $3.5 \times 10^{-5}$ and $n$ is 6.6 . In order to verify the calculation accuracy of the qboiling_cal_1, experimental data, and calculated values from the model were compared and shown in Figure 11.

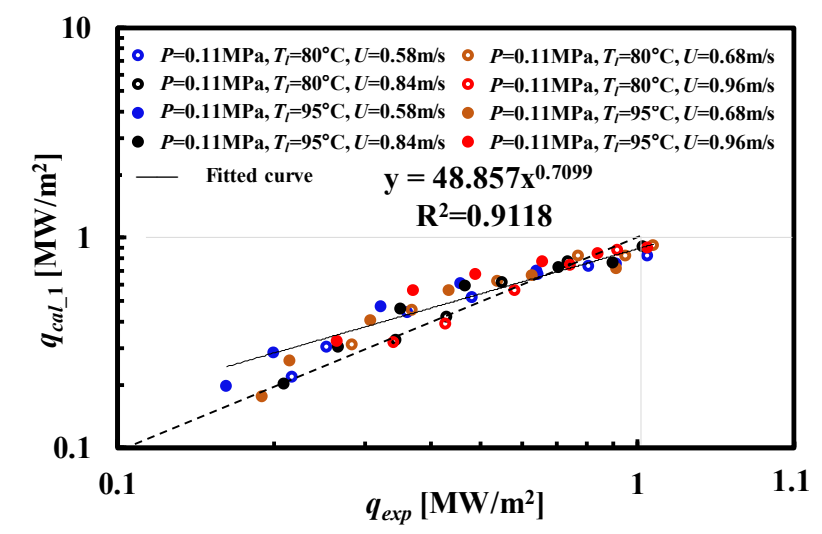

Figure 11 Comparison of predicted surface heat flux using equation (16) and present experimental surface heat flux.

Here, the black dotted line is the function line of $y=x^{1}$, and it is used as the base when calculating the accuracy evaluation. In this case, the coefficient of determination is calculated to be 0.91 , which means that the fitted curve can express the correlation between the two variables well. By comparing the fitted line with the baseline, the index of the independent variable $x$ of the fitted curve is 0.71 , which is 0.29 smaller than the baseline index 1 . Therefore, it is considered that there is an error between the slope of the fitted curve and baseline. Furthermore, the coefficient of the fitted curve is 48.9 and the average relative error is calculated to be $16.0 \%$.

4.4.3. Correlation analysis of Jakob number: Exponential Function Model (EFM)

In order to improve the errors, the results of Figure 10 and Figure 11 are reviewed. As can be seen from these figures, the PFM of $J a$ doesn't have a bad correlation with qboiling_exp, compared with the fitted curve, and the results of equation (16) shown that the PFM can be used to predict heat flux since the average relative error was calculated to be $16 \%$, which is sufficient. Therefore, it is considered that the PFM can be used in heat flux prediction. According to Basu et al. ${ }^{(7)}$, the bubble generation period is also considered as the sum of the bubble growth time and the waiting time between the bubble departure and the next bubble generation. The dimensionless bubble growth time is proposed as a product form of an exponential function of $J a$ and $J a_{\text {sub }}$ as:

$\frac{D_{d}{ }^{2}}{\alpha_{l} t_{g}}=45 J a \exp \left(-0.017 J a_{s u b}\right)$

where $J a_{\text {sub }}$ : subcooled Jakob number [-]. Therefore, combined PFM, the product form of the power function, and the exponential function of $J a$ is considered to be used to predict the heat flux and the equation to calculate the forced flow nucleate boiling heat flux is proposed as follows:

$q_{c a l_{-} 2}=q_{l c}{ }^{*}+q_{\text {boiling_cal_2 }}=q_{l c}{ }^{*}+\beta J a^{m} \exp (\gamma J a)$ 


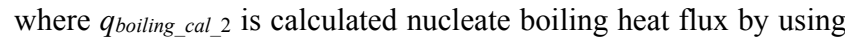
EFM and $\beta, m$ and $\gamma$ are undetermined constants. LMS method by using experimental heat flux $q_{\exp }$ was done, and results were found as $\beta=6.31 \times 10^{-5}, m=5$, and $\gamma=0.151$. The comparison between the predicted and the experimental nucleate boiling heat flux is given in Figure 12. As can be seen, the determination coefficient result is calculated to be 0.89 by using a linear function, hence the product form of the power function and the exponential function of $J a$ is considered to be linear to express the nucleate boiling heat flux well. Furthermore, predicted and measured surface heat fluxes were compared in Figure 13. From Figure 13, the determination coefficient result is calculated to be 0.93 , larger than 0.91 in Figure 11. These results not only express the correlation between the variables well but also the degree of data dispersion is found to be smaller. Comparing with PFM case which is 0.71 , it is close to the index 1 of the baseline. In addition, the coefficient of the fitted curve is calculated to be 7.4, which is significantly lower than 48.9 of the PFM case, and is very close to 1. This result means that the equation (18) predicts the trend of heat flux change more accurately. The relative error calculation results also reflect these improvements, which is calculated to be $11.2 \%$. Therefore, equation (18) is proved that the forced flow nucleate boiling heat flux can be predicted as well as a whole. In order to verify the heat flux curves under different conditions, the comparison of the measured heat fluxes and calculated heat fluxes

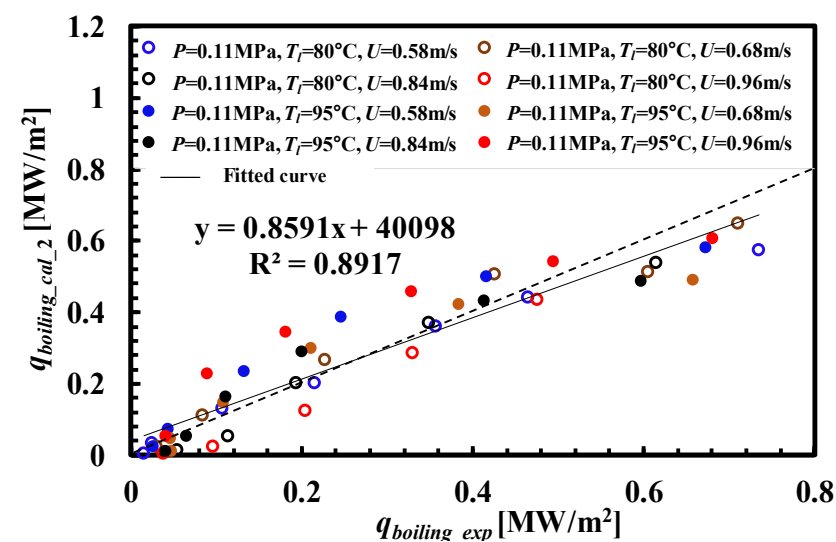

Figure 12 Comparison of predicted nucleate boiling heat flux using qboiling_cal_2 of equation (18) and experimental nucleate boiling heat flux, qboiling_exp.

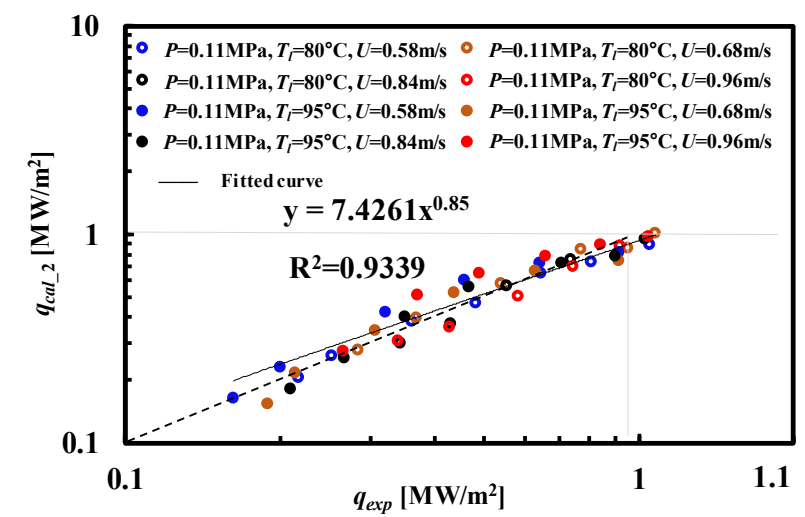

Figure 13 Comparison of predicted surface heat flux using equation (18) and experimental surface heat flux. under the flow velocities of 0.68 and $0.96 \mathrm{~m} / \mathrm{s}$, at coolant temperatures of 80 and $95^{\circ} \mathrm{C}$ are shown in Figures 14 and 15, and the average relative error is shown in Table 4. From Figures 14 and 15 , it can be seen that the changing trend of surface heat flux with the increasing superheat can be reproduced accurately by equation (18) of $J a$. Regarding the quantitative evaluation, the average relative error under the coolant temperature of $80^{\circ} \mathrm{C}$ condition shows a high prediction accuracy with an error rate of $7.3 \%$. Additionally, under the $80{ }^{\circ} \mathrm{C}$ and $0.58 \mathrm{~m} / \mathrm{s}$ condition, the average relative error is found to be $6.5 \%$. Based on the above analysis results, the $J a$ is proved to be an effective dimensionless number for predicting the forced flow nucleate boiling heat flux, can be used to construct the heat flux prediction model.

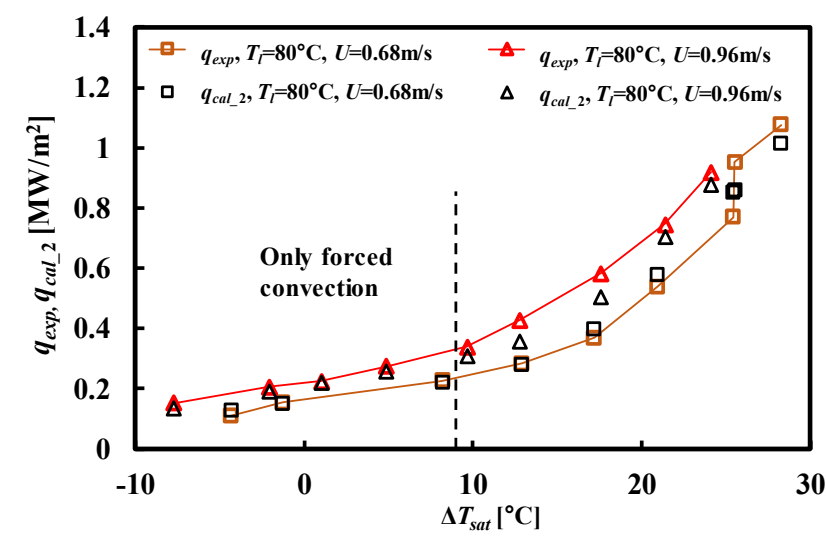

Figure 14 Comparison of predicted surface heat flux using equation (18) and experimental surface heat flux at coolant temperature of $80^{\circ} \mathrm{C}$ and flow velocities of 0.68 and $0.96 \mathrm{~m} / \mathrm{s}$.

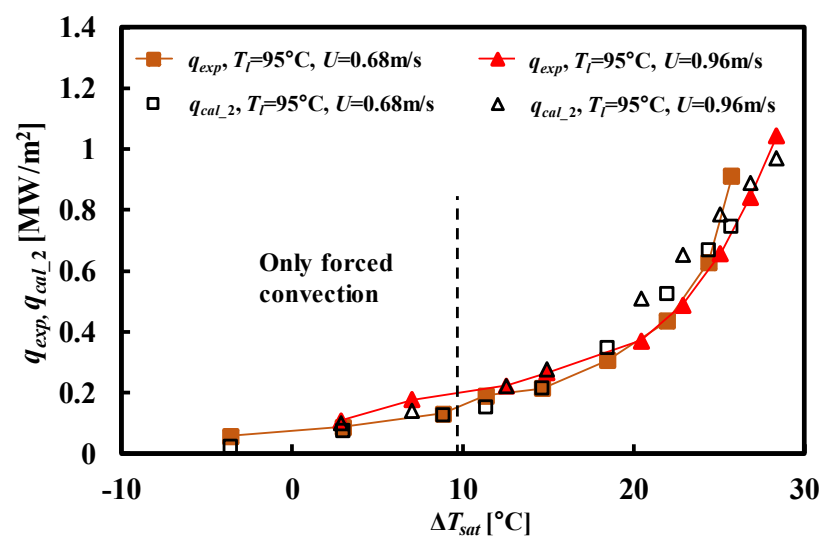

Figure 15 Comparison of predicted surface heat flux using equation (18) and experimental surface heat flux at coolant temperature of $95^{\circ} \mathrm{C}$ and flow velocities of 0.68 and $0.96 \mathrm{~m} / \mathrm{s}$.

Table 4 Comparison of average relative errors from Steiner et al. model and equation (18) at each present experimental condition.

\begin{tabular}{|c||c|c|c|c|}
\hline \multicolumn{1}{|c||}{} & \multicolumn{2}{c|}{ Steiner et al. model } & \multicolumn{2}{c|}{ Equation (18) } \\
\hline \hline$U$ & $80{ }^{\circ} \mathrm{C}$ & $95{ }^{\circ} \mathrm{C}$ & $80{ }^{\circ} \mathrm{C}$ & $95{ }^{\circ} \mathrm{C}$ \\
\hline \hline $0.58 \mathrm{~m} / \mathrm{s}$ & $46.2 \%$ & $36.6 \%$ & $6.5 \%$ & $17.4 \%$ \\
\hline $0.68 \mathrm{~m} / \mathrm{s}$ & $46.8 \%$ & $39.5 \%$ & $7.2 \%$ & $11.7 \%$ \\
\hline $0.84 \mathrm{~m} / \mathrm{s}$ & $48.4 \%$ & $44.1 \%$ & $7.4 \%$ & $10.8 \%$ \\
\hline $0.96 \mathrm{~m} / \mathrm{s}$ & $48.7 \%$ & $45.7 \%$ & $8.6 \%$ & $15.3 \%$ \\
\hline
\end{tabular}




\section{Haoyu Chen et al / International Journal of Automotive Engineering}

Vol.11, No.4(2020)

On the other hand, based on Figures 13-15 and Table 4, it can be seen that the relative errors under the $95{ }^{\circ} \mathrm{C}$ conditions are larger than those under the $80^{\circ} \mathrm{C}$ conditions. This is caused by not considering the influence of the subcooling on the prediction accuracy. In our future study, additional experiments under changing subcooling conditions will be performed, and the relationship between the heat flux and the dimensionless numbers with subcooling as shown in equations (9) and (10) will be discussed. Furthermore, additional experiments will be conducted while changing the influence factors of forced nucleate boiling phenomenon such as: flow velocity, pressure, surface roughness, physical properties of coolant, channel shape, and so forth. Above factors will be evaluated and implemented into dimensionless numbers for constructing a high-accuracy prediction model, which will calculate heat fluxes in ICE cooling system accurately.

\section{Conclusion}

For the purpose of verifying the effective factors for controlling the nucleate boiling heat flux, the experimental apparatus was constructed which can simulate the shape of a ICE coolant channel and the operating conditions of coolant running. The heat flux of the heating surface was measured at different coolant temperature and flow velocity. The dimensionless numbers are constructed by dimensional analysis, and the correlation analysis between the measured data and Jakob number is carried out. The following conclusions can be drawn:

(1)The effects of coolant temperature, flow velocity and superheat on surface heat flux were confirmed by heat flux measurements, and the bubble growth cycle and bubble departure frequency were confirmed with the increase of superheat. Through the verification with measured heat flux, the previous model cannot predict the heat flux in the present experiments and the average relative error is $46.3 \%$.

(2)Some dimensionless number is obtained by dimensional analysis, and the $J a$ is related to the measured nucleate boiling heat flux. As the heat flux prediction result of the correlation based on the $J a$ of the PFM, the whole presents an over-predict tendency and the average relative error is evaluated as $16.0 \%$.

(3)Further analysis shows that the product form of power function and exponential function of $J a$ has a good correlation with the measured heat flux. The average relative prediction error of this model was evaluated as $11.2 \%$. At the coolant temperature of $80{ }^{\circ} \mathrm{C}$, the average error at a flow velocity of $0.58 \mathrm{~m} / \mathrm{s}$ was evaluated as $6.5 \%$.

\section{Acknowledgments}

This work was the result of a collaborative research program with the Research association of Automotive Internal Combustion Engines (AICE) for fiscal year 2019. The authors gratefully acknowledge the concerned personnel.

\section{References}

(1) W.M. Rohsenow, Heat transfer with evaporation, Heat Transfer - A Symposium held at the University of Michigan During the Summer of 1952, University of Michigan Press, pp. 101-150, (1953)

(2) J.C. Chen, A correlation for boiling heat transfer to saturated fluids in convective flow, ASME preprint 63 HT34 presented at the 6th National Heat Transfer Conference, Boston, (1963).

(3) H.K. Forster and N. Zuber, Dynamics of vapor bubbles and boiling heat transfer, AIChE J., Vol.1, pp. 531-535, (1955)

(4) H. Steiner, A. Kobor and L. Gebhard, A wall heat flux model for subcooledboiling flow, Int. J. Heat Mass Transfer, Vol.48, pp. 4161-4173, (2005)

(5) F. W. Dittus and L. M. K. Boelter, Heat transfer in automobile radiators of the tubular type, University of California. Publications in Engineering, Vol.2, No.13, pp.443-461, (1930).

(6) N. Zuber, The dynamics of vapour bubbles in nonuniform temperature fields, Int. J. Heat Mass Transfer, Vol.2, pp.8398, (1961).

(7) N. Basu, G.R. Warrier, V.K. Dhir, Wall heat flux partitioning during subcooled flow boiling: Part1- model development, J. Heat Transfer, Vol.127, pp.131-139, (2005). 